are quite willing to put every confidence in the statements of so accurate and skilful an observer; at the same time we cannot help feeling some regret that he has not been a little more explicit in his description of the sections which lay open the characteristic form of the laccolite. The horizontal base and the undisturbed state of the underlying strata are the first points on which we wish to be thoroughly assured. It is stated that "in five instances one side of the dome of strata has been washed away, exposing the core of trachyte to its base, and showing undisturbed strata beneath." We do not doubt the statement, but we should have been better satisfied if these cases had been described more in detail in the special account of the separate mountains. The views of the Marvine laccolite in Figs. 43 and 44, if we understand them aright, do seem to be conclusive on the point of the horizontal base; but the evidence would have been more convincing if these plates had been explained at greater length in the text. In fact, the one fault we have to find with the book is the difficulty of understanding the illustrations; they are not striking from an artistic point of view ; in some the letters of reference are so indistinct that they can be found only with the utmost difficulty, and we confess that by some we have been fairly beaten; we should, for instance, very much like to know which is the laccolite in Fig. 33 .

Again, the evidence for the parallelism between the upper surface of the laccolite and the bedding of the overlying rocks, has hardly been brought out with sufficient distinctness ; after a comparison, for instance, of Figs. 25 and 26 , an invidious critic might have something severe to say about the proportion which the part of the laccolite actually seen bears to that which is admittedly theoretical.

But we have made these remarks in no captious spirit; we wish merely to express our fear that the acceptance of Mr. Gilbert's ingenious speculations may be hindered by a lack of detail in the statement of the evidence he brings forward in support of them.

Assuming Mr. Gilbert's theory to be sound and good, it is not likely that the Henry Mountains are the only ones constructed on the laccolitic type. Mr. Gilbert is inclined to class under this head a number of mountains in the western territories, grouped together under one type by Dr. A. C. Beale, in a paper in No. 3 vol. iii. of the Bulletin of the United States Geological Survey. We cannot say that there is anything in Dr. Beale's description which would lead us to assign these mountains to the laccolitic group; and in one case, that of the Elk Mountains, the careful account given in the Report for 1874 of the Geological and Geographical Survey of the Territories, seems to show that they form a normal mountain range ridged up by horizontal pressure.

There is one problem which has been always more or less of a puzzle to the student of volcanic phenomena, on which Mr. Gilbert's speculations may possibly throw considerable light: we mean the formation of pit-craters. Mr. Scrope showed how these singular depressions had probably been blown out by one single explosion of unusual violence, and Mr. Judd has suggested their connection with intrusive sheets. If we suppose a rapid accumulation of lava in a laccolitic mass, and a sudden development within it of steam of high tension, we shall have exactly the conditions suitable for producing one of those explosions which there is every reason to think have been the cause of pit-craters.

The work contains a long and elaborate chapter on "Earth Sculpture," which space will not allow us to do more than mention, and concludes with a chapter on Economics, in which the author insists with almost pathetic earnestness, that the Henry Mountains, full of interest as they are for the geologist, can never be put to any profitable account commercially, unless possibly in parts for grazing. Nature would seem here to have laid herself out to frame a district which should have attractions for no one but the student of pure science.

A. H. G.

\section{FINNIC ETHNOLOGY}

$A$ DECIDED stage in the progress of Finnish studies $\mathrm{A}$ is marked by the sumptuous work on "Finnish Crania," recently published by the native ethnologist, Gustavus Retzius. ${ }^{1}$ Continuing the investigations of his father, Anders Retzius, this distinguished anthropologist has at last been enabled to arrive at some definite conclusions both as regards the type itself and its geographical area. The elder writer was a warm advocate of what may be called the Finno-European theory, which is still popular amongst a certain school of fearless anthropologists, and which, since the discovery of the Cuneiform writings, has received a fresh impulse and a wider extension. This is not the place to discuss the angry question of the FinnoUgrian relations to the Accad language and civilisation of Babylonia. But many enthusiasts will probably be disappointed to hear that the younger writer abandons his father's position, and deals a severe blow to the doctrine of a former wide-spread diffusion of the Finnish race over the greater part of Central and Western Europe. The laborious attempts of many ingenious philologists to discover traces of Ugrian affinities in the Italic and Teutonic tongues, and even to remove the Etruscan from the Aryan to the Ural-Altaic family, can scarcely be regarded as at all successful. On the other hand, a few ancient skulls presenting certain traits characteristic of the same race, together with some hatchets and other stone implements picked up here and there analogous in form to those often dug up in Finland, offered far too flimsy materials to supply a solid basis for such a vast superstructure. Hence it is not perhaps surprising that in the light of further investigation and more serious research the theory should prove to be somewhat visionary.

History had already pointed out that during the ascendency of the Goths from the Baltic to the Euxine the Finns were found nowhere to the west, but only to the east and north of that line ; in fact in their present homes on the Volga, in Finland, round about the great Russian lakes, and more recently along the southern shores of the Gulf of Finland. It might doubtless be argued that at this period the race had farther west been already absorbed by the Slavs and Teutons of Aryan stock, intruders from Asia. But no reliable data can be appealed to in support of this position. The authenticity of the stone hammers and other objects of Oriental form said to have been found in France and elsewhere is now questioned, while the philological argument never gets beyond the purely etymological stage.

Hence Gustavus Retzius adopts the view now fast gaining ground, that instead of being the aborigines of Western and Central Europe, the Finns are amongst the most recent arrivals from Asia. Their own traditions point to the Altai region as their true home; the national usages and the spirit of the popular songs embodied in the great epic, the Kalevala, are all Asiatic rather than European, and the uninterrupted stream of their migrations westwards may still be clearly followed from their most advanced outposts in the Scandinavian peninsula through Finland, along the Volga and Kama valleys, over the Urals, and up the Obi basin to the probable cradle of their race in the Sayan highlands.

The narrower, though scarcely less interesting question of the position of the Finnic branch in the Ural-Altaic family is still surrounded with difficulties, which seem to be intensified rather than removed by the conclusions of M. Retzius. While the Finnish language is no doubt fundamentally connected with those of the other members of the group, the physical features of the race present “ "Finska Kranier." Skildrade af Gustaf Retzius, Stockholm, 1878. 
many striking deviations from the ordinary Mongol standard. The elder Retzius had long ago distinguished four more or less marked ethnical groups in Finland itself, apart altogether from the intruding Swedes, Russians, and other foreigners. These, however, are now reduced to two only, which a careful investigation of the materials supplied by archæology, tradition, the Norse Sagas, the old national songs and philology, combined with an extensive study of a vast number of crania and living subjects, have enabled the younger writer to fix with some approach to precision.

Of the two, the Tavastian and the Karelian, he regards the latter as the genuine national type, in this differing from the commonly received opinion. The Karelians, occupying the country more to the east, are of slighter build, but better proportioned and taller than the Tavastians, of a light brown complexion, with longer head, narrower and less heavy features, long, straight, and pointed nose, dark hazel eyes, chestnut or dark hair falling in ringlets over the shoulders, open and animated expression, though still with a serious cast. The Tavastian, on the contrary, is of a much more solid, cumpact, and coarse build, middle size, light or ashy complexion, but always lacking the 'rosy tints peculiar to the Teutonic peoples, with straight silken hair of a flaxen colour, and often yellow at the tips, broad square head, short snub nose, dilated nostrils, slightly oblique greyish blue eyes, sullen and unsympathetic expression.

This description obviously corresponds far more closely with the common Mongoloid type than does that of the Karelians. Yet in the writer's opinion the latter are the true descendants of Illmarinen, the hero of the Kalevala, and the scene of his exploits is laid in the region still occupied by them. The Tavastians he regards as a distinct ethnical element of doubtful affinities, though allied on the one hand with the Esthonians of the Baltic provinces, on the other possibly with the Lapps of the Arctic regions.

The question, as already remarked, has been advanced one stage; but much remains to be done before we can expect to see all the difficulties removed by which it is surrounded. Meanwhile it seems impossible to agree with M. Retzius, that the Karelians, rather than the Tavastians, represent the true Finnish type. Both have, no doubt, largely absorbed foreign elements. But if both are alike branches of the Mongolo-Tatar family, as has been hitherto supposed, and as their speech appears to place beyond question, it follows that of the two the Tavastians must be regarded as the nearest to the common stock. The Karelians are, of course, much the finer race, both physically and intellectually, and national prejudice may, therefore, feel inclined to regard them as the purer branch. But, ethnologists will probably be disposed to look on the improvements as due rather to a greater absorption of foreign elements, Teutonic or Slav, if not Lithuanian. They occupy a country which may well have been peopled by some of these races before their arrival, whereas the dreary lacustrine region of Tavastland must have been all but destitute of inhabitants previous to its occupation by the advanced wave of Finnish migration.

A. H. KEANE

\section{RESEARCHES ON TELEPHONE VIBRA- TIONS}

$\mathrm{D}^{\mathrm{R}}$ RUDOLPH KONIG, the well-known constructor of acoustical apparatus, has recently brought before the Physical Society of Paris a research of the highest interest, upon the difference of phase which exists between the vibrations of a transmitting and a receiving telephone. In a paper published more than two years ago, Prof. du Bois-Reymond discussed the conditions which determine the intensity and the phase of different sounds transinitted telephonically; and from theoretical considerations deduced the conclusion that sounds of low pitch suffered greater loss by transmission than shrill ones, and that every simple vibration was retarded in phase by a quarter of an undulation. The former of these actions would produce an alteration in the timbre of the voice as received at the end of the line : the latter effect would remain unappreciated by the ear, since the retardation of phase was the same for waves of all periods. More recently Helmholtz has attacked the question in a paper in the Annalen of Wiedemann ("Telephon und Klangfarbe"), and, with a theoretical treatment of the question based upon somewhat deeper analysis, has deduced the results that all sounds are weakened by transmission in almost a constant proportion irrcspective of their pitch, and that the difference of phase between the vibrations of transmitter and receiver are very small. Dr. König has endeavoured to put these conflicting speculations to the test of experiment, and with marked success.

It may be well, perhaps, to indicate the elementary considerations which led du Bois-Reymond to predict the existence of this hitherto unobserved difference of phase. The currents by which sounds are carried from the transmitter to the receiver in the Bell telephone are induction currents, excited in a coil of insulated wire by the vibrations of the iron diaphragm in front of the permanent magnet which serves as a core. The intensity of these induced currents is greatest when the vibrating diaphragm is moving with the greatest velocity. But the maximum velocity of the diaphragm does not occur at the moment when the displacement of the diaphragm is greatest. To non-mathematical readers this fact may be explained by reference to the movements executed by a simple pendulum. As the pendulum swings backwards and forwards the "bob" comes absolutely to rest at the moment when its displacement to one side or the other is the greatest, and it moves with the greatest velocity when it passes through the "point of rest" mid-way between its two extreme positions. Mathematically, the matter is equally simply stated. The displacement of a body executing a simple harmonic motion is determined by an equation of the form $u=a \cos \frac{2 \pi t}{\mathrm{~T}}$, where the values of $u$ pass through a regular series of maximum and minimum values as $t$ increases. These successive values are geometrically represented by the heights of the ordinates of the well-known harmonic curve or sinusoid, the distances along the horizontal axis $0 x$ being proportional to the times. Thus the telephone diaphragm originally at rest begins to move towards the magnet under the influence of the voice. The displacement, which at the origin is nothing, increases until at $A$ it becomes a maximum. Owing to its elasticity the diaphragm flies back, and passing rapidly through its point of starting suffers a displacement in an opposite sense. These movements are graphically represented on the harmonic

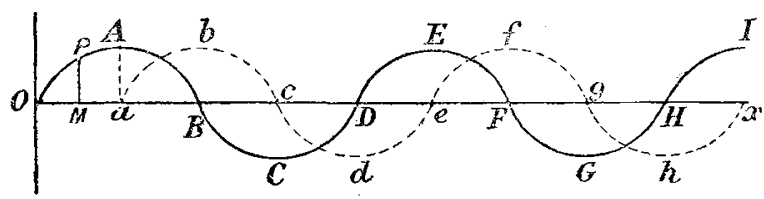

curve by the passage of the curve across the axis at $B$ to its minimum or greatest negative displacement at $\mathrm{C}$, the curve recurring from the point $D$. Now the equation which represents the velocity of the moving point will be obtained from the equation of the displacement by differentiating with respect to time. This gives us an equation of the form-

$$
\dot{u}=-\frac{2 a \pi}{\mathrm{T}} \sin \frac{2 \pi t}{\mathrm{~T}}=\frac{2 a \pi}{\mathrm{T}} \cos \left(\frac{2 \pi t}{\mathrm{~T}}+\frac{\pi}{2}\right),
$$

